\title{
Differential expression of miRNA in rat myocardial tissues under psychological and physical stress
}

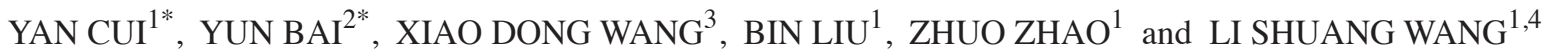 \\ ${ }^{1}$ Department of Cardiology, The Second Hospital of Jilin University, Changchun, Jilin 130041; \\ ${ }^{2}$ Institute of Genetics and Cytology, School of Life Sciences, Northeast Normal University, Changchun, Jilin 130024; \\ ${ }^{3}$ Department of Endoscopy, The Second Hospital of Jilin University, Changchun, Jilin 130041; ${ }^{4}$ Department of Cardiology, \\ The General Hospital of CNPC in Jilin, Jilin, Jilin 132022, P.R. China
}

Received August 18, 2013; Accepted January 13, 2014

DOI: $10.3892 /$ etm.2014.1504

\begin{abstract}
In the current study, microRNA (miRNA) microarrays were used to detect differentially expressed miRNAs in the myocardial tissues of rat models under stress, to screen target miRNA candidates for miRNA therapy of stress-induced myocardial injury. Rats were bound and suspended in order to induce acute stress (AS) and chronic stress (CS) models. miRNA microarrays were used to detect differentially expressed miRNA in the myocardial tissues of the stressed and control groups. In comparison to the normal control, there were 68 differentially expressed miRNAs in the AS model, of which 32 were upregulated and 36 were downregulated. There were 55 differentially expressed miRNAs in the CS model, of which 20 were upregulated and 35 were downregulated. Of the 123 miRNAs, 15 miRNAs were differentially expressed between the AS and CS groups, of which four were significantly upregulated (rno-miR-296, rno-miR-141, rno-miR-382 and rno-miR-219-5p) and 11 were downregulated (significantly downregulated, rno-miR-135a and rno-miR-466b). The stress of being bound and suspended induces myocardial injury in the rats. Myocardial injury may cause the differential expression of certain miRNAs. Psychological stress may lead to the significant upregulation of rno-miR-296, rno-miR-141, rno-miR-382 and rno-miR-219-5p in addition to the significant downregulation of miR-135a and miR-466b.
\end{abstract}

Correspondence to: $\mathrm{Mr}$ Xiao Dong Wang, Department of Endoscopy, The Second Hospital of Jilin University, 126 Xiantai Street, Changchun, Jilin 130041, P.R. China

E-mail: wangxd1981@163.com

Dr Bin Liu, Department of Cardiology, The Second Hospital of Jilin University, 218 Ziqiang Street, Changchun, Jilin 130041, P.R. China E-mail: liubin3333@vip.sina.com

Key words: stress, microRNAs, myocardium, rat, microarray

\section{Introduction}

Stress is a non-specific systemic adaptive response of the body stimulated by a variety of internal and external environmental, social and psychological factors, also known as the stress response. Sympathetic and parasympathetic nervous system balance and hypothalamic-pituitary-adrenal (HPA) axis function alter under stress stimulation (1). Furthermore, external stimuli signals are delivered through multiple pathways or channels into the cells and trigger a series of cell reactions, including protein synthesis, degradation and cytokine secretion $(2,3)$. These cause cardiomyocyte proliferation and hypertrophy or apoptosis, resulting in myocardial injury.

microRNA (miRNA) is small non-coding RNA of 18-26 bp. miRNA causes the degradation of, or inhibits the translation of, target mRNA by pairing with specific bases of the target mRNA and is thus involved in the post-transcriptional regulation of gene expression $(4,5)$. Studies have observed that miRNA expression has temporal and tissue specificity (1-6). miRNA is important in various developmental stages of the cardiovascular system, regulating cardiomyocyte proliferation, differentiation and apoptosis under physiological and pathological conditions (7-19). Dozens of miRNAs have been identified in myocardial cells, including miR-133a, miR-133b, miR-1d, miR-296, miR-21, miR-208 and miR-195 (4-18). Studies have demonstrated that miRNA has an important role in the regulation of heart development, cardiac hypertrophy, cardiac electrophysiology and angiogenesis. The use of myocardial genomic research in the study of stress-induced myocardial injury may improve the understanding of the mechanisms of stress-induced myocardial injury. However, there are currently no reports on the role of miRNA underlying stress-induced myocardial injury.

In the present study, rat models of myocardial injury induced by psychological stress were established and miRNA microarrays were used to analyze the changes in the miRNA expression profiles of injured myocardial tissues. Furthermore, the role of miRNA in stress-induced myocardial injury was studied and an attempt was made to locate the target miRNAs which regulate stress-induced myocardial injury, which may provide the basis for the development of new drugs for the prevention and treatment of stress-induced myocardial injury. 
Table I. Purity of RNA in NC, AS and CS models.

\begin{tabular}{lcccccc}
\hline Sample ID & $\mathrm{OD}_{260 / 280}($ ratio & $\mathrm{OD}_{260 / 230}($ ratio $)$ & Concentration, ng/ $\mu 1$ & Volume, $\mu 1$ & Quantity, ng & QC result (pass/fail) \\
\hline $\mathrm{NC} 1$ & 2.03 & 2.24 & $1,063.73$ & 15 & $15,955.95$ & Pass \\
$\mathrm{NC} 2$ & 2.07 & 2.22 & $1,589.88$ & 25 & $39,747.00$ & Pass \\
$\mathrm{AS}$ & 2.06 & 2.22 & $1,533.42$ & 50 & $76,671.00$ & Pass \\
$\mathrm{CS}$ & 2.09 & 2.14 & $1,376.56$ & 15 & $20,648.40$ & Pass \\
\hline
\end{tabular}

NC, normal control; AS, acute stress; CS, chronic stress; OD, optical density; QC, quality control.

\section{Materials and methods}

Animals. A total of 24 eight-week-old male Wistar rats with body weights of $220 \pm 10 \mathrm{~g}$ were supplied by the Experimental Animal Center of Jilin University Norman Bethune Medical Division (Changchun, China). The laboratory was disinfected, quiet and well-ventilated. The animals were provided with free access to food and water and were housed at a temperature of $22 \pm 2^{\circ} \mathrm{C}$, with $50 \%$ humidity and a $12 \mathrm{~h}$ natural light-dark cycle. The rats were randomly divided into the normal control group $(\mathrm{NC} ; \mathrm{n}=8)$, the chronic stress group (CS; $\mathrm{n}=8$ ) and the acute stress group (AS; $\mathrm{n}=8$ ). The Jilin University Animal Ethics Committee approved the protocol for this study (no. 2012036).

Modeling. The method for modeling stress in a rat has been described previously (21). For CS modeling, the limbs of the rat were bandaged to a board, with the tail kept free; subsequently the rats were hung upside down and denied access to food and water randomly for $2 \mathrm{~h}$ each day for 14 consecutive days. For AS modeling, the rats fasted for $12-24 \mathrm{~h}$ with access to water, and were subsequently hung upside down with their limbs bound to a board for $6 \mathrm{~h}$. In all groups, blood was collected and the concentration of adrenocorticotropic hormone (ACTH) was determined using an ELISA kit (R\&D, Minneapolis, MN, USA) in order to assess the stress state effect of the model.

Statistical processing for this section was performed as follows: the SPSS 16.0 software package (IBM Corp., Chicago, IL, USA) was used for statistical analysis and measurement data were stated as the mean \pm standard deviation. Comparisons were performed using the mean adopted t-test, and $\mathrm{P}<0.01$ was considered to indicate a statistically significant difference.

Extraction and qualification of total RNA. The rats underwent thoracotomies under anesthesia in order to remove their hearts. The hearts were washed using $0.2 \mathrm{~mol} / \mathrm{l}$ phosphate buffer saline (pH 7.0) and stored in liquid nitrogen. Next, 100 mg myocardial tissues were frozen and crushed using a BioPulverizerTM (Aoran Technology LTD, Shanghai, China), mixed with $1 \mathrm{ml}$ TRIzol reagent (Invitrogen Life Technologies, Carlsbad, CA, USA), and homogenized. Total RNA was extracted using the TRIzol reagent method. Extracted RNA was dissolved in RNAse-free water and incubated at $60^{\circ} \mathrm{C}$ for $10 \mathrm{~min}$.

Absorbance at 260, 280 and $230 \mathrm{~nm}$ was measured using an ultraviolet spectrophotometer (ND-1000; NanoDrop, Wilmington, DE, USA). $\mathrm{A}_{260} / \mathrm{A}_{280}$ and $\mathrm{A}_{260} / \mathrm{A}_{230}$ ratios were calculated to determine the purity of RNA. The RNA concentration was calculated according to the formula:
$\mathrm{A}_{260} \times 40 \mathrm{ng} / \mu \mathrm{l}$. Denaturing agarose gel electrophoresis was performed. Briefly, $3 \mu \mathrm{g}$ RNA were samples stored in RNAse-free water mixed with formaldehyde-containing loading buffer (containing $10 \mu \mathrm{g} / \mathrm{ml}$ ethidium bromide) at a volume ratio of $1: 3$ and immediately incubated at $70^{\circ} \mathrm{C}$ for $15 \mathrm{~min}$ in order to denature the samples. Electrophoresis was performed at a voltage of $6 \mathrm{~V} / \mathrm{cm}$ for 10-15 min, and gel images were captured using a gel image processing system (UVP EC3 600 Imaging System, UVP LLC, Upland, CA, USA).

miRNA labeling. miRNA was labeled using the miRCURYTM Array Power Labeling kit (cat no. 208032-A; Exiqon, Inc., Woburn, MA, USA) in accordance with the manufacturer's instructions. Briefly, $4 \mu 1$ calf intestine phosphatase (CIP) reaction solution $(1 \mu \mathrm{l}$ total RNA, $0.5 \mu \mathrm{l}$ CIP buffer, $0.5 \mu \mathrm{l}$ CIP

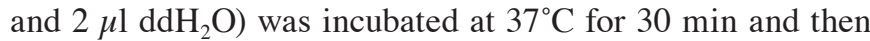
at $95^{\circ} \mathrm{C}$ for $1 \mathrm{~min}$ to terminate the reaction, and immediately placed in an ice bath for $10 \mathrm{~min}$. Following mild centrifugation (Sigma 4K 15CR; $200 \mathrm{x} \mathrm{g}$ ), $3 \mu \mathrm{l}$ labeling buffer, $1.5 \mu \mathrm{l}$ fluorescent labels (Hy3 $3^{\mathrm{TM}}$ for the stress group or $\mathrm{Hy} 5^{\mathrm{TM}}$ for the control), $2 \mu 1$ DMSO and $2 \mu 1$ labeling enzyme were sequentially added in an ice bath. The system was incubated at $16^{\circ} \mathrm{C}$ for $1 \mathrm{~h}$ and subsequently at $65^{\circ} \mathrm{C}$ for $15 \mathrm{~min}$ in order to terminate the labeling reaction, and stored at $4^{\circ} \mathrm{C}$ following mild centrifugation.

miRNA microarray hybridization and scanning. The labeled RNAs and miRCURY Array chip (Shanghai Kangcheng BioEngineering Co., Ltd., Shanghai, China) were hybridized in accordance with the manufacturer's instructions. Briefly, $180 \mu 1$ reaction mixture $(25 \mu 1$ labeled miRNA, $90 \mu 12 \mathrm{X}$ hybridization buffer and $65 \mu$ l nuclease-free buffer) was incubated at $95^{\circ} \mathrm{C}$ in the dark for $2 \mathrm{~min}$ and subsequently placed in an ice bath for $10 \mathrm{~min}$. At the same time, the miRCURY Array chip was assembled according to the manufacturer's instructions (Shanghai Kangcheng BioEngineering Co., Ltd.). The reaction mixture was loaded through the loading port and the $1 \mathrm{X}$ hybridization buffer was used to fill the hybridization chamber. The microarray chip was packaged in a protective bag and placed vertically into water $\left(95^{\circ} \mathrm{C}\right)$ for $12 \mathrm{~h}$, followed by drying in an oven at $56^{\circ} \mathrm{C}$ over night. The chip was washed using the miRCURY Array Wash Buffer kit (cat no. 208021, Exiqon, Inc., Woburn, MA, USA) according to the manufacturer's instructions, followed by centrifugation at $200 \mathrm{x} \mathrm{g}$ for $5 \mathrm{~min}$ to dry the chip. The scanning procedure was performed using an Axon GenePix 4000B microarray scanner (Axon 
Table II. Upregulated miRNA in the AS and CS models.

A, Upregulated miRNA (AS).

\begin{tabular}{lrc}
\hline Name & ID & Ratio scale slide 1 (AS/NC1) \\
\hline rno-miR-21 & 5740 & 1.584 \\
rno-miR-132 & 10937 & 4.004 \\
rno-miR-141 & 10946 & 1.732 \\
rno-miR-19a & 10997 & 1.627 \\
rno-miR-221 & 11022 & 1.600 \\
rno-miR-223 & 11024 & 2.198 \\
rno-miR-31 & 11052 & 1.504 \\
rno-miR-32 & 11053 & 1.716 \\
rno-miR-379 & 11093 & 1.669 \\
rno-miR-129 & 11200 & 1.844 \\
rno-miR-322 & 11225 & 1.524 \\
rno-miR-336 & 11266 & 1.612 \\
rno-miR-201 & 13176 & 1.679 \\
rno-miR-376b-3p & 14304 & 1.725 \\
rno-miR-382 & 14307 & 2.007 \\
rno-miR-147 & 17411 & 1.732 \\
rno-miR-21 & 17896 & 1.697 \\
rno-miR-139-5p & 27542 & 1.618 \\
rno-miR-34b & 29153 & 1.693 \\
rno-miR-674-3p & 31053 & 1.503 \\
rno-miR-34c & 32772 & 1.882 \\
rno-miR-219-5p & 42509 & 1.701 \\
rno-miR-291a-3p & 42595 & 2.026 \\
rno-miR-20b-5p & 42640 & 1.730 \\
rno-miR-296 & 42713 & 1.997 \\
rno-miR-324-3p & 42719 & 1.602 \\
rno-miR-347 & 42763 & 1.907 \\
rno-miR-451 & 42866 & 1.548 \\
rno-miR-20a & 42876 & 2.142 \\
rno-miR-107 & 46629 & 1.566 \\
rno-miR-20a & 46793 & 4639 \\
rno-miR-375 & 46918 & \\
\hline
\end{tabular}

B, Upregulated miRNA (CS).

\begin{tabular}{lcc}
\hline Name & ID & Ratio scale slide 2(CS/NC2) \\
\hline rno-miR-141 & 10946 & 2.128 \\
rno-miR-182 & 10975 & 1.528 \\
rno-miR-194 & 10988 & 1.838 \\
rno-miR-377 & 11091 & 1.579 \\
rno-miR-448 & 11113 & 2.067 \\
rno-miR-351 & 11235 & 1.636 \\
rno-miR-344-3p & 11268 & 2.615 \\
rno-miR-381 & 14306 & 1.686 \\
rno-miR-382 & 14307 & 1.676 \\
rno-miR-200c & 17427 & 1.726 \\
rno-miR-877 & 30033 & 2.082 \\
rno-miR-25 & 42481 & 2.027 \\
rno-miR-219-5p & 42509 & 1.519
\end{tabular}

Table II continued.

\begin{tabular}{lcc}
\hline Name & ID & Ratio scale slide 2 (CS/NC2) \\
\hline rno-miR-671 & 42525 & 2.098 \\
rno-miR-330 & 42606 & 2.212 \\
rno-miR-615 & 42690 & 2.269 \\
rno-miR-296 & 42713 & 2.231 \\
rno-miR-218 & 42815 & 1.923 \\
rno-miR-219-2-3p & 42834 & 2.271 \\
rno-miR-471 & 42916 & 2.519 \\
\hline
\end{tabular}

$\mathrm{NC}$, normal control; AS, acute stress; CS, chronic stress.

Instruments, Inc., Foster City, CA, USA) to obtain the scanning profiles, followed by data analysis and analysis of the significant difference using GenePix Pro6.0 software (Axon Instruments, Inc.).

Data processing and analysis. An experienced operator utilized the GenePix Pro6.0 software for data processing and analysis. The signal points included in the subsequent analysis should conform to two prerequisites: i) The signal intensity of the red and green channels is $>0$; and ii) the signal to noise ratio (SNR) of the two channels is $>1$, or either SNR is $>2$. The weak signal points that did not conform to the two prerequisites were excluded from the subsequent analysis. miRNA was also excluded provided it contained 3 or 4 weak signal points in a total of four repeat points.

Lowess standardization (intra-chip standardization) was performed to remove dye intensity-dependent deviation. Scale standardization (inter-chip standardization) was used to reduce the experimental or sample errors between the different chips. Four repeat points in the chip were merged by calculating the median of the $\mathrm{Hy} 5 / \mathrm{Hy} 3$ ratio of each point. Subsequently the differentially expressed miRNAs were determined using the statistical Student t-test. $\mathrm{P}<0.05$ was considered to indicate a statistically significant difference. Fold change (stress/control) $\geq 1.5$ indicated upregulation and $<0.67$ indicated downregulation.

\section{Results}

Modeling. Rats in the AS group appeared to be in a stressed state immediately following the surgery, but in the CS group, stress appeared after five days. The HPA system excites the stress stimulus and may be involved in abnormal secretion of corticotropin-releasing hormone $(\mathrm{CRH}), \mathrm{ACTH}$ and three glucocorticoid hormones. The paraventricular nucleus of the hypothalamus secretes CRH under stress. The adenohypophysis $\mathrm{CRH}$ receptors perceive the change in ACTH and cause the adrenal cortex to secrete ACTH. ACTH is a key hormone of the HPA axis. Therefore, ACTH was selected to evaluate the stress state. As shown in Fig. 1, the ACTH levels of the stress model group increased significantly compared with the control group $(\mathrm{P}<0.01)$, indicating that the model was in a stressed state. ACTH levels of the AS model increased significantly compared with the CS model $(\mathrm{P}<0.05)$. 
Table III. Downregulated miRNA AS and CS models.

Downregulated miRNA(AS)

\begin{tabular}{|c|c|c|}
\hline Name & ID & Ratio scale slide 1 (AS/NC1) \\
\hline rno-miR-146a & 10952 & 0.6450 \\
\hline rno-miR-184 & 10978 & 0.6700 \\
\hline rno-miR-300-3p & 11221 & 0.6230 \\
\hline rno-miR-325-5p & 11226 & 0.6000 \\
\hline rno-miR-329 & 11227 & 0.4570 \\
\hline rno-miR-341 & 11229 & 0.6137 \\
\hline rno-miR-297 & 11262 & 0.4580 \\
\hline rno-miR-344-3p & 11268 & 0.6310 \\
\hline rno-miR-338 & 17825 & 0.5270 \\
\hline rno-miR-667 & 28944 & 0.6034 \\
\hline rno-miR-708 & 29190 & 0.2780 \\
\hline rno-miR-877 & 30033 & 0.5100 \\
\hline rno-miR-761 & 32608 & 0.3230 \\
\hline rno-miR-129 & 42467 & 0.5560 \\
\hline rno-miR-204 & 42502 & 0.5240 \\
\hline rno-miR-296 & 42528 & 0.6610 \\
\hline rno-miR-196a & 42538 & 0.6040 \\
\hline rno-miR-342-5p & 42576 & 0.4370 \\
\hline rno-miR-466c & 42586 & 0.4200 \\
\hline rno-miR-330 & 42606 & 0.6210 \\
\hline rno-miR-30b-3p & 42626 & 0.4800 \\
\hline rno-miR-878 & 42645 & 0.6120 \\
\hline rno-miR-490 & 42703 & 0.4800 \\
\hline rno-miR-325-3p & 42706 & 0.4530 \\
\hline rno-miR-294 & 42707 & 0.6310 \\
\hline rno-miR-34c & 42767 & 0.5980 \\
\hline rno-miR-665 & 42770 & 0.3530 \\
\hline rno-miR-150 & 42802 & 0.5930 \\
\hline rno-miR-300-5p & 42826 & 0.5880 \\
\hline rno-miR-135a & 42839 & 0.2680 \\
\hline rno-miR-125b & 42845 & 0.6360 \\
\hline rno-miR-743b & 42864 & 0.6190 \\
\hline rno-miR-330 & 42875 & 0.4010 \\
\hline rno-miR-551b & 42917 & 0.4400 \\
\hline rno-miR-466b & 42933 & 0.3010 \\
\hline rno-miR-742 & 42963 & 0.6440 \\
\hline
\end{tabular}

Downregulated miRNA (CS)

\begin{tabular}{lcc}
\hline Name & ID & Ratio Scale Slide 2(CS/NC2) \\
\hline rno-miR-9 & 4040 & 0.5790 \\
rno-miR-21 & 5740 & 0.5540 \\
rno-miR-130a & 10138 & 0.6440 \\
rno-miR-146b & 10306 & 0.6080 \\
rno-miR-136 & 10943 & 0.3230 \\
rno-miR-142-3p & 10947 & 0.4850 \\
rno-miR-146a & 10952 & 0.6090 \\
rno-miR-193 & 10986 & 0.5680 \\
rno-miR-204 & 11005 & 0.4770
\end{tabular}

Table III continued.

\begin{tabular}{|c|c|c|}
\hline Name & ID & Ratio Scale Slide 2 (CS/NC2) \\
\hline rno-miR-31 & 11052 & 0.3610 \\
\hline rno-miR-33 & 11062 & 0.5510 \\
\hline rno-miR-363 & 11077 & 0.4930 \\
\hline rno-miR-341 & 11229 & 0.6460 \\
\hline rno-miR-297 & 11262 & 0.5910 \\
\hline rno-miR-10a-5p & 13485 & 0.4630 \\
\hline rno-miR-488 & 17316 & 0.5520 \\
\hline rno-miR-147 & 17411 & 0.5190 \\
\hline rno-miR-425 & 17608 & 0.6640 \\
\hline rno-miR-338 & 17825 & 0.6350 \\
\hline rno-miR-142-5p & 19015 & 0.6220 \\
\hline rno-miR-106b & 19582 & 0.6570 \\
\hline rno-miR-199a-5p & 19590 & 0.5520 \\
\hline rno-miR-10a-3p & 28019 & 0.5170 \\
\hline rno-miR-872 & 28250 & 0.6700 \\
\hline rno-miR-144 & 29802 & 0.6640 \\
\hline rno-miR-761 & 32608 & 0.5430 \\
\hline rno-miR-129 & 42467 & 0.6670 \\
\hline rno-miR-29b-1 & 42479 & 0.6100 \\
\hline rno-miR-136 & 42512 & 0.4920 \\
\hline rno-miR-338 & 42592 & 0.5560 \\
\hline rno-miR-325-3p & 42706 & 0.6570 \\
\hline rno-miR-150 & 42802 & 0.5740 \\
\hline rno-miR-135a & 42839 & 0.1210 \\
\hline rno-miR-330 & 42875 & 0.6280 \\
\hline rno-miR-466b & 42933 & 0.3620 \\
\hline
\end{tabular}

NC, normal control; AS, acute stress; CS, chronic stress.

Extraction and qualification of total RNA. The $\mathrm{A}_{260} / \mathrm{A}_{280}$ ratio of RNA solution is a method for detecting RNA purity and values close to 2.0 are considered to represent pure RNA. A ratio $<1.8$ indicates sample contamination. A ratio $>2.0$ indicates RNA hydrolysis. The ratio range between 1.8 and 2.1 is acceptable. In addition, the $\mathrm{A}_{260} / \mathrm{A}_{230}$ ratio should be $>1.8$ for pure RNA. As demonstrated in Table I, the extracted RNAs conformed to the quality standards discussed and thus qualified for the subsequent miRNA experiments. On the denaturing gel, the $28 \mathrm{~S}, 18 \mathrm{~S}$ and $5.8 \mathrm{~S}$ ribosomal RNA (rRNA) bands were bright (Fig. 2), and the rRNA bands demonstrated no signs of impurity. This indicated that the extracted total RNA was complete, RNA degradation and contamination were low, and the extracted total RNA exhibited high levels of purity and were of sufficient quality to qualify for use in subsequent miRNA experiments.

Differential expression of miRNAs. According to data processing and analysis, specific miRNAs were identified to be differentially expressed in the stress model by comparing them with the normal control group (Tables II and III). There were 68 differentially expressed miRNAs in AS model, of these, 32 were upregulated and 36 were downregulated; there 


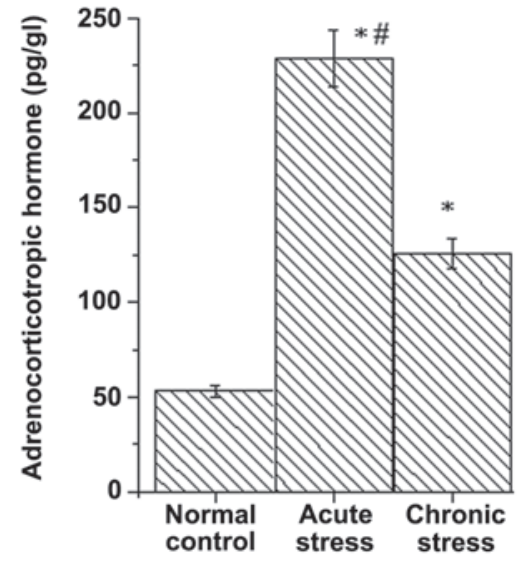

Figure 1. Adrenocorticotropic hormone concentrations in models/ Data are presented as mean \pm standard deviation $(\mathrm{pg} / \mathrm{ml} ; \mathrm{n}=8)$. ${ }^{*} \mathrm{P}<0.01$, vs. normal control; ${ }^{\#} \mathrm{P}<0.05$, chronic stress group.

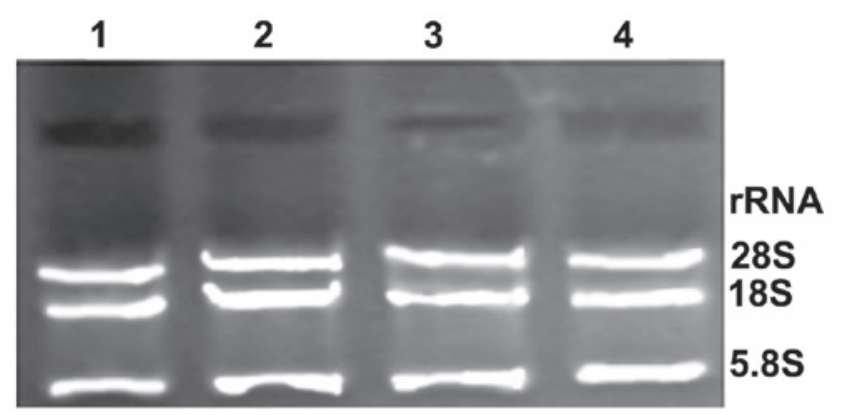

Figure 2. Ribosomal RNA separations on denaturing agarose gel. Lanes 1-4: $\mathrm{NC} 1, \mathrm{NC} 2$, acute stress group, chronic stress group, respectively. NC, normal control.

were 55 differentially expressed miRNAs in the CS model, of these, 20 were upregulated and 35 were downregulated. Of the 123 miRNAs, 15 were differentially expressed in the AS and CS model groups, of these, four were significantly upregulated (rno-miR-296, rno-miR-141,rno-miR-382 and rno-miR-219-5p; Table IV) and 11 were downregulated (significantly downregulated, rno-miR-135a and rno-miR-466b; Table V).

\section{Discussion}

Excessive psychological stress leads to myocardial injury by changing the function of the sympathetic nervous system and the HPA axis. Studies have demonstrated that miRNA expression is tissue-specific and is involved in the formation and maintenance of tissue specificity during biological development (4-18). In myocardial cells numerous miRNAs have been identified to have an important role in the various developmental stages of the cardiovascular system by regulating cardiomyocyte proliferation, differentiation and apoptosis under physiological and pathological conditions (1-3).

The present study analyzed miRNA expression profiles in the myocardial tissues of AS and CS rat models using miRNA microarray technology and identified specific differentially expressed miRNAs. In the differentially expressed miRNAs of the AS and CS models, 15 miRNAs were differentially expressed in the AS and CS models. Of these
Table IV. Upregulated miRNA in the AS and CS models.

\begin{tabular}{lccc}
\hline Name & \multicolumn{2}{c}{$\begin{array}{c}\text { Ratio scale } \\
\text { slide 1(AS/NC1) }\end{array}$} & $\begin{array}{c}\text { Ratio scale } \\
\text { slide 1(CS/NC2) }\end{array}$ \\
\hline rno-miR-141 $^{\mathrm{a}}$ & 10946 & 1.732 & 2.128 \\
rno-miR-382 $^{\mathrm{a}}$ & 14307 & 2.007 & 1.676 \\
rno-miR-219-5p $^{\mathrm{a}}$ & 42509 & 1.701 & 1.519 \\
rno-miR-296 $^{\mathrm{a}}$ & 42713 & 1.997 & 2.231 \\
\hline
\end{tabular}

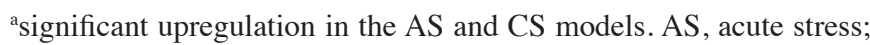
CS, chronic stress; NC, normal control.

Table V. Downregulated miRNA in the AS and CS models.

\begin{tabular}{lccc}
\hline Name & \multicolumn{2}{c}{$\begin{array}{c}\text { Ratio scale } \\
\text { slide 1 (AS/NC1) }\end{array}$} & $\begin{array}{c}\text { Ratio scale } \\
\text { slide 1 (CS/NC2) }\end{array}$ \\
\hline rno-miR-135a $^{\text {a }}$ & 42839 & 0.268 & 0.121 \\
rno-miR-466b $^{\text {a }}$ & 42933 & 0.301 & 0.362 \\
rno-miR-146a & 10952 & 0.645 & 0.609 \\
rno-miR-341 & 11229 & 0.614 & 0.646 \\
rno-miR-338 & 17825 & 0.527 & 0.635 \\
rno-miR-761 & 32608 & 0.323 & 0.543 \\
rno-miR-129 & 42467 & 0.556 & 0.667 \\
rno-miR-325-3p & 42706 & 0.453 & 0.657 \\
rno-miR-150 & 42802 & 0.593 & 0.574 \\
rno-miR-330 & 42875 & 0.401 & 0.628 \\
rno-miR-297 & 11262 & 0.458 & 0.591 \\
\hline
\end{tabular}

asignificant downregulation in AS and CS. AS, acute stress; CS, chronic stress; $\mathrm{NC}$, normal control.

15 miRNAs, rno-miR-296, rno-miR-141, rno-miR-382 and rno-miR-219-5p were significantly upregulated, particularly miR-296 (Table IV), and 11 were downregulated (miR-135a and miR-466b were significantly downregulated, particularly miR-135a; Table V). These results indicate that miRNA changes caused by stress-induced myocardial injury are different from the miRNA changes caused by other factors. Therefore, the application of a reasonable stress-induced animal model, to explore the changes in the miRNAs of myocardial tissues under stress and identify specifically expressed miRNAs, is conducive to the further use of RNA interference for the treatment of stress-induced cardiovascular complications.

miR-125b, miR-146, miR-150, miR-199a, miR-21, miR-129, miR-341 and miR-451 have been confirmed to play an important role in the different developmental stages of the cardiovascular system (4-18). They are also significantly differentially expressed in the stress-induced model established in this study, indicating that these miRNAs may be common targets for myocardial injury caused by various factors. Stress can cause myocardial injury, thus leading to changes in these miRNAs. This finding also confirmed that stress itself is an important factor for myocardial injury. 
In two stress-induced models, rno-miR-296 was the most significantly upregulated and miR-135a was the most significantly downregulated. Würdinger et al (19) observed that miR-296 may reduce the level of hepatocyte growth factor-regulated tyrosine kinase substrate (HGS) and induce the decrease in expression level of HGS-mediated vascular endothelial growth factor receptor-2 (VEGFR2) and platelet-derived growth factor receptor $\beta$ by interacting with the substrate mRNA of target HGS. miR-296 promotes upregulation of VEGFR and contributes to angiogenesis. In addition, the inhibition of miR-296 has been found to reduce angiogenesis of xenograft tumors (19). In the present study, psychological stress-induced myocardial injury led to the upregulation of miR-296.

NR3C2 is a ligand-dependent transcription factor associated with steroid hormones. The transcription factor regulates the balance of water and ions and affects blood pressure by regulating water-sodium retention. Sõber et al (21) verified that NR3C2 may be the target gene of miR-135a and is involved in the regulation of blood pressure by inhibiting the in vitro translation of $\mathrm{NR} 3 \mathrm{C} 2$ to regulate the angiotensin-aldosterone system balance. In the present study, miR-135a was significantly downregulated. We hypothesized that miR-135a may interact with the target genes to inhibit sympathetic nerve excitation and suppress the HPA axis and the renin-vascular angiotensin system, resulting in the release of a variety of stress hormones, including catecholamines, cortical hormone, pancreatic glucagon and renin, thus protecting the myocardium from injury.

In conclusion, rno-miR-296, rno-miR-141, rno-miR-382, rno-miR-219-5p, miR-135a and miR-466b may be involved in stress at the molecular level, thus causing myocardial injury. The development of stress-induced myocardial injury is a complex biological process and involves a variety of mechanisms. After cells receive external stimuli, stimulatory signals are transferred through multiple pathways or channels into the cells, causing a series of reactions. Altering the conditions in these cells may lead to the activation of the cell death pathway, particularly the activation of the mitochondrial death mechanism, causing a death cascade reaction, which includes cell necrosis and apoptosis. miRNA may cause degradation of the target mRNA or inhibit its translation by pairing with the specific base of target mRNA and thus play a role in post-transcriptional regulation. Multiple miRNAs can jointly regulate the same target gene, and multiple target genes are capable of interacting with the same miRNA. By regulating the level of mRNA transcription, miRNA controls the amount of protein synthesis, thus regulating the occurrence and development of cardiovascular diseases. Once the specific miRNA is screened out, the target gene may be predicted. Furthermore, cardiomyocytes of miRNA inhibition and overexpression, following gene transfer using the miRNA mimic and miRNA inhibitors methods, may be cultured in vitro to explore the relationship between the miRNA and target genes in cardiomyocytes, which the authors believe should be studied further. The specific miRNAs found in the present study are the key to the further study of miRNA function.

\section{Acknowledgements}

This study was funded by a grant from the National Natural Science Foundation of China (no. 30940041).

\section{References}

1. Mann DL: MicroRNAs and the failing heart. N Engl J Med 356: 2644-2645, 2007.

2. Thum T, Galuppo P, Wolf C, et al: MicroRNAs in the human heart: a clue to fetal gene reprogramming in heart failure. Circulation 116: 258-267, 2007.

3. Carlson TR, Feng Y, Maisonpierre PC, Mrksich M and Morla AO: Direct cell adhesion to the angiopoietins mediated by integrins. J Biol Chem 276: 26516-26525, 2001.

4. Chen JF, Mandel EM, Thomson JM, et al: The role of microRNA-1 and microRNA-133 in skeletal muscle proliferation and differentiation. Nat Genet 38: 228-233, 2006.

5. Zhao Y, Ransom JF, Li A, et al: Dysregulation of cardiogenesis, cardiac conduction, and cell cycle in mice lacking miRNA-1-2. Cell 129: 303-317, 2007

6. Harfouche R, Gratton JP, Yancopoulos GD, Noseda M, Karsan A and Hussain SN: Angiopoietin-1 activates both antiand proapoptotic mitogen-activated protein kinases. FASEB J 17: $1523-1525,2003$

7. Carè A, Catalucci D, Felicetti F, et al: MicroRNA-133 controls cardiac hypertrophy. Nat Med 13: 613-618, 2007.

8. van Rooij E, Sutherland LB, Liu N, et al: A signature pattern of stress-responsive microRNAs that can evoke cardiac hyportrophy and heart failure. Proc Natl Acad Sci USA 103: 18255-18260, 2006.

9. Thum T, Gross C, Fiedler J, et al: MicroRNA-21 contributes to myocardial disease by stimulating MAP kinase signalling in fibroblasts. Nature 456: 980-984, 2008.

10. Tatsuguchi M, Seok HY and Callis TE: Expression of microRNAs is dynamically regulated during cardiomyocyte hypertrophy. J Mol Cell Cardiol 42: 1137-1141, 2007.

11. Sayed D, Rane S, Lypowy J, et al: MicroRNA-21 targets Sprouty2 and promotes cellular outgrowths. Mol Biol Cell 19: 3272-3282, 2008.

12. Cheng Y, Ji R, Yue J, Yang J, Liu X, Chen H, Dean DB and Zhang C: MicroRNAs are aberrantly expressed in hypertrophic heart: do they play a role in cardiac hypertrophy? Am J Pathol 170: 1831-1840, 2007.

13. Fiedler U, Reiss Y, Scharpfenecker M, et al: Angiopoietin-2 sensitizes endothelial cells to TNF-alpha and has a crucial role in the induction of inflammation. Nat Med 12: 235-239, 2006.

14. van Rooij E, Sutherland LB, Qi X, Richardson JA, Hill J and Olson EN: Control of stress-dependent cardiac growth and gene expression by a microRNA. Science 316: 575-579, 2007.

15. Duisters RF, Tijsen AJ, Schroen B, et al: miR-133 and miR-30 regulate connective tissue growth factor: implications for a role of microRNAs in myocardial matrix remodeling. Circ Res 104: 170-178, 2009.

16. Lin Z, Murtaza I, Wang K, Jiao J, Gao J and Li PF: miR-23a functions downstream of NFATc3 to regulate cardiac hypertrophy. Proc Natl Acad Sci USA 106: 12103-12108, 2009.

17. Harris TA, Yamakuchi M, Ferlito M, Mendell JT and Lowenstein CJ: MicroRNA-126 regulates endothelial expression of vascular cell adhesion molecule 1. Proc Natl Acad Sci USA 105: 1516-1521, 2008.

18. Wang S, Aurora AB, Johnson BA, et al: The endothelial-specific microRNA miR-126 governs vascular integrity and angiogenesis. Dev Cell 15: 261-271, 2008 .

19. Würdinger T, Tannous BA, Saydam O, et al: miR-296 regulates growth factor receptor overexpression in angiogenic endothelial cells. Cancer Cell 14: 382-393, 2008

20. Chico TJ, Milo M and Crossman DC: The genetics of cardiovascular disease: new insights from emerging approaches. J Pathol 220: 186-197, 2010.

21. Sõber S, Laan M and Annilo T: MicroRNAs miR-124 and miR-135a are potential regulators of the mineralocorticoid receptor gene (NR3C2) expression. Biochem Biophys Res Commun 391: 727-732, 2010. 